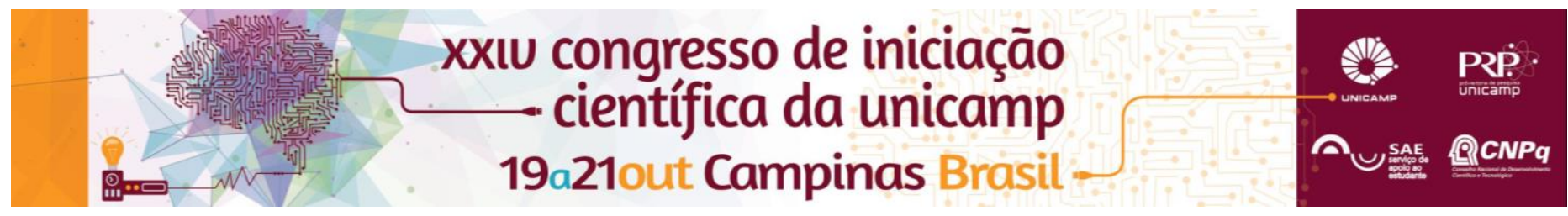

\title{
Papéis de gênero na contracepção: uma revisão sistemática sobre a percepção dos adolescentes homens
}

\author{
Luna Serena A. Pereira, Rodolfo Pacagnella.
}

\begin{abstract}
A adolescência é marcada pelas transformações principalmente no âmbito sexual que exigem maior atenção dos familiares e dos profissionais da saúde, devido a suas repercussões, como a gravidez precoce. Todavia, a abordagem da questão é focalizada no ponto de vista feminino, mas ao se considerar a gravidez na adolescência como um fenômeno social, é importante entender a participação masculina na contracepção. Foi realizada uma revisão sistemática nas bases de dados Scielo e Pubmed sobre o papel de gênero na contracepção. Após a extração, os dados dos artigos selecionados foram avaliados quanto à percepção de gênero dos homens adolescentes na decisão pela contracepção. Ao todo 16 artigos foram incluídos, dos quais 9 foram realizados no Brasil, 4 na África subsaariana e 3 nos Estados Unidos. Observou-se que ainda há a manutenção do antigo padrão de atribuição da responsabilidade reprodutiva à mulher, o que ainda é uma grande barreira para a adoção de práticas contraceptivas na adolescência.
\end{abstract}

\section{Key words:}

adolescência, contracepção, gênero.

\section{Introdução}

A adolescência é marcada pelas transformações corporais e hormonais que fazem a transição entre a infância e a idade adulta. As modificações intensas desse período, principalmente no âmbito sexual, exigem maior atenção dos familiares e dos profissionais da saúde, devido a suas repercussões, como a gravidez precoce. A incidência da gravidez na adolescência está relacionada com as mudanças no comportamento e valores relativos às relações entre os gêneros, à sexualidade e às concepções de família. Todavia, a abordagem da questão é focalizada no ponto de vista feminino, como comprova a própria construção do conceito de "gravidez na adolescência": uma jovem entre 10 e 20 anos incompletos engravida, independentemente da idade de seu parceiro. O tema é constantemente focado na perspectiva feminina, sendo "maternidade" e "gravidez" usados como sinônimos.

Embora diversas pesquisas apontem as características dos parceiros de adolescentes grávidas, a literatura carece de análises sobre a gravidez na adolescência do ponto de vista masculino, como, por exemplo, de quem foi a iniciativa do uso de métodos contraceptivos (se esta ocorreu). Isso enfatiza a crença errônea de que a gravidez e sua prevenção cabem apenas às mulheres, excluídos os homens de tal responsabilidade. No entanto o cenário de mudanças do papel social feminino e concomitantemente de permanência de alguns aspectos tradicionais associados à mulher e à maternidade contribui para que as adolescentes tenham dificuldade quanto à escolha de suas ações. Ao se considerar a gravidez na adolescência como um fenômeno social, é importante entender outras facetas do problema como a participação masculina na contracepção e a concepção de paternidade que meninos e meninas têm nesse momento da vida.

\section{Métodos}

Foi realizada uma revisão sistemática nas bases de dados Scielo e Pubmed sobre o papel de gênero na contracepção. Foram utilizados os termos gravidez na adolescência, contracepção na adolescência, paternidade na adolescência, maternidade na adolescência e gênero adaptados para cada base de dados. Não foram utilizados filtros e restrições. Após a extração, os dados dos artigos selecionados foram avaliados quanto à percepção de gênero dos homens adolescentes na decisão pela contracepção.

\section{Resultados e Discussão}

Foram selecionados 29 artigos pelo Scielo. Após a leitura dos títulos, 15 artigos foram selecionados para avaliar o resumo dos quais 11 foram lidos na íntegra e 7 selecionados para a avaliação. No pubmed a estratégia de busca resultou 89 artigos dos quais 9 foram incluídos na revisão após a análise de título, resumo e leitura na íntegra. Ao todo 16 artigos foram incluídos, dos quais 9 foram realizados no Brasil, 4 na África subsaariana e 3 nos Estados Unidos. Apenas 1 artigo tinha um componente quantitativo, os demais eram de metodologia qualitativa. De forma geral os artigos apontam que os garotos adolescentes não se preocupam com a contracepção, sendo a "confiança" na parceira um dos principais balizadores da relação para a introdução de cuidados. Ainda há a manutenção do antigo padrão de atribuição da responsabilidade reprodutiva à mulher $\mathrm{e}$ não é incomum os parceiros comprarem as pílulas e guardá-las como forma de controle. No tentando os adolescentes casados e alguns grupos étnicos têm mais possibilidade de discutir o uso de contraceptivos e planejamento familiar com suas parceiras.

\section{Conclusões}

Embora haja situações em que a discussão do planejamento familiar é compartilhada entre homens e mulheres, os adolescentes homens ocupam uma posição privilegiada de poder no exercício da sexualidade em detrimento das mulheres. A manutenção do antigo padrão de atribuição da responsabilidade reprodutiva à mulher ainda é uma grande barreira para a adoção de práticas contraceptivas na adolescência.

\section{Agradecimentos}

Financial support for the project was provided by CNPq. 